\title{
Uma tradução comentada do artigo "A Termodinâmica Oculta das Partículas" de Louis de Broglie
}

\author{
Portuguese translation of Louis de Broglie's article "The hidden thermodynamics of particles" \\ with comments
}

\author{
Nathan W. Lima*1] João Paulo M. C. Chaib²@ \\ ${ }^{1}$ Universidade Federal do Rio Grande do Sul, Departamento de Física, Porto Alegre, RS, Brasil. \\ ${ }^{2}$ Centro Federal de Educação Tecnológica de Minas Gerais, Departamento de Formação Geral, Timóteo, MG, Brasil.
}

\begin{abstract}
Recebido em 08 de julho de 2021. Revisado em 03 de setembro de 2021. Aceito em 13 de setembro de 2021.
Louis de Broglie é principalmente lembrado por sua contribuição no que se refere à dualidade onda-partícula e à expressão que relaciona o momento linear e o comprimento de onda no desenvolvimento da Teoria Quântica, contribuições dadas no período de 1922-1924. Entretanto, pouco se fala de sua postura e atividade crítica a interpretações afins da Complementaridade de Niels Bohr, e sua proposta de novas bases para uma teoria quântica alternativa, de caráter realista e determinista. Assim, no sentido de apresentar textos históricos originais e contribuir para o resgate das ideias de Louis de Broglie, apresentamos uma tradução comentada do artigo "A Termodinâmica Oculta das Partículas", publicado em 1964, em que de Broglie sintetiza sua proposta teórica e apresenta dois resultados importantes, a saber: que o caminho de menor ação percorrido por uma partícula é aquele que maximiza a entropia do meio subquântico; e que os estados de transição em um átomo teria uma entropia menor do que os estados estacionários, justificando termodinamicamente porque os estados estacionários têm maior probabilidade de acontecerem.
\end{abstract}

Palavras-chave: De Broglie, teoria quântica, realismo, termodinâmica, relatividade.

Louis de Broglie is mainly remembered for his contribution regarding the wave-particle duality and the expression that relates linear momentum and wavelength in the development of Quantum Theory, contributions given in the period 1922-1924. However, little is said about his posture and critical activity to related interpretations of Niels Bohr's Complementarity, and his proposal of new bases for an alternative quantum theory, with a realistic and deterministic character. Thus, in order to present original historical texts and contribute to the rescue of Louis de Broglie's ideas, we present a commented translation of the article "The Hidden Thermodynamics of Particles", published in 1964, where de Broglie summarizes his theoretical proposal and presents two important results, namely: that the path of least action taken by a particle is the one that maximizes the entropy of the subquantum medium; and that transition states in an atom would have a lower entropy than steady states, thermodynamically justifying why steady states are more likely to happen. Tradução do resumo para o inglês. Keywords: De Broglie, quantum theory, realism, thermodynamics, relativity.

\section{Introdução}

No final do século XIX e início do século XX, três grandes áreas da Física - Mecânica, Termodinâmica e Eletromagnetismo - se apresentavam com um satisfatório conjunto de teorias com o objetivo de descrever e aplicar em grande escala os fenômenos observados. Esse sucesso normalmente é confundido como produto de uma unicidade epistemológica na Física, o que não era o caso. Na época em questão, existiam bases teóricas concorrentes nessas áreas, fruto de diferentes visões de mundo, assumindo ou privilegiando diferentes pressupostos ontológicos e epistemológicos para a concepção de seus modelos e previsões.

Em especial, pode-se notar uma tensão crescente, nesse período, entre as escolas de pensamento que privi-

\footnotetext{
* Endereço de correspondência: nathan.lima@ufrgs.br
}

legiavam a noção das interações da matéria como sendo mediadas por entes contínuos preenchendo-a, contra as vertentes com uma visão granular - como uma dicotomia entre matéria e vazio - cuja síntese de sua interação direta seria o movimento. Dentro da primeira vertente estavam os "cartesianos" e defensores da Naturphilosophie - que acreditavam uma descrição mais "orgânica" ou "holística" desse contínuo - tal como as visão de energeticistas como Hermann von Helmholtz (18211894) e Wilhelm Ostwald (1853-1932). Na segunda escola estavam os "newtonianos" e os "atomistas", como os estudos de Mecânica Estatística desenvolvidos por Ludwig Von Boltzmann (1844-1906).

Mais especificamente, Boltzmann buscava, em seu programa, explicar a termodinâmica, e, principalmente a segunda lei da Termodinâmica (a qual envolve a noção de processos irreversíveis e um sentido preferencial para processos espontâneos), a partir de um ponto de 
vista essencialmente mecânico. Tal visão se opunha aos estudos iniciais de tal lei, feita por Nicolas Carnot (1796-1832) o qual se baseou na noção da existência do fluido termodinâmico chamado "calórico" para desenvolvê-la [1, 2]. Boltzmann conseguiu mostrar que a maximização da entropia não seria algo obrigatório, mas que o estado de equilíbrio, portanto de maior entropia, seria simplesmente muito mais provável do que outros estados.

Ao mesmo tempo, a concepção de campos contínuos ganhava um arcabouço mais coerente a partir do Tratado de Eletromagnetismo de Maxwell, publicado em 1873, gerando uma alternativa para a então consagrada descrição por partículas e forças - típicas da mecânica newtoniana - e tornando-se hegemônica aos fins do século XIX.

Nesse contexto, Albert Einstein (1879-1955), no início do século XX, dedicou-se, principalmente, a um programa de pesquisa na área de Termodinâmica e Mecânica Estatística. De 1902 a 1904, ele produziu artigos extremamente importantes sobre tais temas, avançando em conceitos fundamentais, independentemente de Boltzmann e Gibbs [3, 4]. Na sequência, em 1905, Einstein aplicou esse mesmo quadro teórico para estudar a radiação eletromagnética por uma perspectiva granular, propondo o conceito de quantum, isto é, a energia da radiação eletromagnética foi tratada como um conjunto de "quantidades" localizadas no espaço [5]. Dessa forma, pode-se perceber, a partir da discussão de Einstein, uma incompatibilidade essencial entre os pressupostos ontológicos assumidos por Maxwell e Boltzmann.

É da tentativa de Einstein de aproximar dois campos consolidados da Física, que assumiam pressupostos ontológicos distintos, que inicia-se o que denominamos, hoje, de Teoria Quântica. Muitos problemas que apareceram ao longo do século XX ao decorrer de tal Teoria ainda se referem à impossibilidade de compatibilizar noções atomistas e continuístas.

Parte dos embates sobre o problema da radiação de corpo negro e o quantum de Einstein foram travadas no encontro de Solvay de 1911, do qual participava Maurice de Broglie (1875-1960), um físico experimental, estudioso das propriedades da radiação X. Seu irmão mais novo, Louis de Broglie (1892-1987), tendo acesso às atas do evento, passou a se dedicar ao estudo da Física teórica e ao entendimento do problema que estava sendo levantado.

Em 1922, L. de Broglie fez uma importante análise teórica da radiação de corpo negro adotando uma perspectiva puramente corpuscular, e de 1923 a 1924, passou a tratar os sistemas físicos de forma dual, como uma partícula com um campo vibratório associado [6] 8. Nesse momento, ele já não falava mais somente de fótons, mas de qualquer partícula. Todo corpo teria um campo vibratório associado, o qual, devido às transformações das coordenadas espaciais e temporal segundo as transformações de Lorentz, é interpretado como uma onda em um referencial para o qual o corpo está em movimento. Nesses trabalhos, Louis de Broglie compara a transformação da frequência de um relógio de acordo com a transformação de Lorentz, medida com um oscilador harmônico, por exemplo, $\nu^{\text {ohs }}=\nu_{0}^{\text {ohs }} / \gamma$, com a transformação da frequência presente na equação de Planck-Einstein $E=h \nu$. Pela transformação da energia $E=E_{0} \gamma$, a frequência do movimento vibratório associado à partícula quântica deve ser $\nu=\nu_{0} \gamma$. Então, de Broglie observa que a frequência associada à energia se transforma diferentemente da frequência de um relógio e é análoga à transformada aplicada a uma onda. Para resolver essa aparente contradição, o cientista francês indica como necessário associar um grupo de ondas a cada partícula (ver também [9]).

Nos anos subsequentes, entretanto, o embate entre a visão corpuscular e ondulatória entraria de novo no centro da disputa pela interpretação da Teoria Quântica. Por um lado, Werner Heisenberg (1901-1976) iniciou o desenvolvimento a Mecânica Matricial em 1925, apoiado nas noções de salto quântico e, principalmente, no Princípio de Correspondência de Niels Bohr (1885-1962).

No mesmo período, de 1926-1928, Erwin Schrödinger (1887-1961) desenvolveu sua Mecânica Ondulatória, pressupondo que o elétron (e a radiação eletromagnética) são grupos de ondas (não havendo qualquer corpúsculo) [10] - uma visão praticamente antagônica à de Heisenberg.

Entende-se, de uma forma geral, que, na busca do amálgama entre tais visões antitéticas (corpuscular e ondulatória), duas grandes sínteses foram propostas [11. A primeira, uma síntese positivista, tendendo mais ao idealismo, foi defendida pela Escola de Copenhague, protagonizada por Niels Bohr (1885-1962) e seu Princípio da Complementaridade. Nessa visão, as ondas discutidas por Louis de Broglie e Schrödinger teriam um caráter probabilístico e não corresponderiam a um ente material no mundo. Schrödinger, Einstein ou de Broglie nunca concordaram totalmente com tal interpretação.

A segunda síntese, na busca por um caráter materialista, foi desenvolvida inicialmente por de Broglie, em uma proposta dualista-realista [11. Em especial, em 1927, de Broglie apresentou a proposta que ficou conhecida como "onda piloto" ou solução dupla, em que de Broglie mantém a existência de um "corpúsculo" (como uma singularidade no campo) e um campo ondulatório pelo qual o corpúsculo é transportado. Assim, a Mecânica Ondulatória e a interpretação probabilística de Born forneceriam apenas a descrição do campo piloto [12, p. 226]:

Minha concepção é semelhante àquela que foi brilhantemente sustentada pelo Sr. Born no sentido que ela conduz a considerar as soluções contínuas como fornecendo as probabilidades de presença, mas difere em um ponto 
essencial. Para o Sr. Born, de fato, existem apenas probabilidades; o determinismo dos fenômenos individuais deve ser abandonado, sendo determinada apenas a probabilidade dos fenômenos estatísticos. No modo de ver aqui adotado, ao contrário, o ponto material é uma realidade essencial e seu movimento é inteiramente determinado como sendo ele uma singularidade de amplitude em uma onda que se propaga.

A conferência de Solvay de 1927, entretanto, a qual sediou o famoso debate entre Einstein e Bohr, foi um episódio fundamental para a deslegitimação de outras visões sobre a Teoria Quântica que não a Interpretação de Copenhague. No artigo traduzido neste trabalho, Louis de Broglie narra justamente o fato de que ele haveria se rendido ao grupo de Copenhague em 1927. Apesar disso, de Broglie seguiu nas décadas subsequentes, criticando a interpretação de Copenhague, e na década de 1940, publicou artigos sobre a Mecânica Estatística e a Mecânica Ondulatória, tentando resgatar uma visão determinista para explicar a probabilidade inerente à Teoria Quântica, como Boltzmann queria fazer com a Termodinâmica 13 .

Teve-se, na comunidade científica, um novo ímpeto para a interpretação determinista da Teoria Quântica após 1952, quando David Bohm (1917-1992) publicou sua interpretação das variáveis ocultas [14, 15]. Vale a pena destacar o artigo Model of the Causal Interpretation of Quantum Theory in Terms of a Fluid with Irregular Fluctuations [16] em 1954, quando Bohm era pesquisador na USP, que publicou com Jean-Pierre Vigier (1920-2004). Nesse trabalho, eles assumem que a interpretação hidrodinâmica de Madelung (aquela que trata a equação de Schrödinger como uma equação de escoamento de um fluido) trata de um fluido real. Logo na sequência, surgiram diversas pesquisas buscando uma interpretação realista e se dedicando a explicar as partes dos problemas quânticos que são ignorados pela Escola de Copenhague, como o que acontece durante a transição de estado quântico. Tais pesquisas foram conduzidas por pesquisadores como Georges Lochak (1930-2021) e João Luís Andrade e Silva (1928-2017).

É nesse contexto, motivado pelos resultados do Bohm e dos demais autores, que de Broglie decidiu resgatar sua interpretação causal. Ele próprio discute sua retomada à construção de uma teoria determinista para Teoria Quântica [17, p. 963]:

Reafirmação da interpretação da Mecânica Ondulatória pela teoria da solução dupla, que o autor, recomeçando as suas tentativas de 1924-1927, procurou desenvolver com a colaboração de vários jovens cientistas. Alguns resultados recentemente obtidos são especialmente evidenciados, em conexão com novos pontos de vista, que chamaram a atenção do autor desde suas declarações dos anos 1954-1955.

Nessa retomada de seu programa original, de Broglie se dedicou a criticar as interpretações puramente probabilísticas e a resolver as principais questões da Teoria Quântica a partir de sua proposta causal [18, 19].

Ao longo desse processo, fica claro para de Broglie que, da mesma forma que Boltzmann tentou explicar de forma mecânica as relações estatísticas que descrevem sistemas macroscópicos, a descrição probabilística sugerida pela Teoria Quântica deveria, de alguma forma, também estar associada a um problema termodinâmico. Ademais, a Teoria Quântica e sua interpretação usual descrevem sistemas nos seus "autoestados"; mas não fala nada sobre os processos de transição entre estados, o que é muito similar ao que se faz no contexto da Termodinâmica do equilíbrio. Tal analogia por si só sugere que os autoestados possam ser descritos como estados de maior entropia em uma descrição termodinâmica.

Em 1961, de Broglie deu o primeiro passo na construção de sua termodinâmica da partícula isolada, quando apresentou um artigo com o seguinte resumo: "O autor expõe ideias teóricas que permitiriam vincular o princípio da mínima ação ao segundo princípio da Termodinâmica".

Nos anos subsequentes, de Broglie avançou em sua proposta em diferentes artigos [20, 21], e publicou um livro dedicado exclusivamente ao tema, no mesmo ano do artigo cuja tradução apresentamos neste trabalho [22].

Neste trabalho, apresentamos a tradução do artigo La thermodynamique "cachée» des particules [23]. Uma versão traduzida recentemente para o inglês pode ser encontrada em [24]. Nós fizemos uma tradução a partir do francês. Uma discussão mais completa está no livro "A Termodinâmica da partícula isolada" (La thermodynamique de la particule isolée) [22, 25]. Outro artigo muito similar a este foi publicado em inglês por de Broglie em 1970 sob o título "A reinterpretação da Mecânica Ondulatória" (The reinterpretation of wave mechanics) [26].

Esperamos contribuir para o resgate da proposta original de Louis de Broglie, a qual se compromete com uma interpretação dissidente em relação à interpretação majoritária da Teoria Quântica. Ao longo da tradução, apresentamos comentários e reflexões para contribuir para a compreensão do artigo.

\subsection{Novo interesse: As gotas errantes}

Com o desenvolvimento das técnicas de observação por câmeras ultra-rápidas têm-se revelado uma série de fenômenos de interesse para área da Física em escala macroscópica [27]. Dentro do fenômenos estudados, destacamos o fenômeno das "gotas errantes" (walking droplets). Se uma gota for puxada de um fluido em vibração e abandonada sobre ele, dependendo do grau de agitação vertical do fluido, essa gota age como uma 
partícula independente e "quica indefinidamente" sobre ele [28]. Caso essa partícula desenvolva uma velocidade horizontal, ela "caminhará" sobre o fluido produzindo sobre ele uma frente de onda que, por sua, vez interfere no movimento da gota gerando um macro estado dual "partícula-onda" 29]. Isso acontece de tal maneira que permite a observação do desenvolvimento do padrão de difração depois de, uma por uma, as gotas passarem por uma fresta e colidir com um anteparo 30. A analogia não para por aí, o fenômeno das "gotas errantes" permitiu a observação em macroescala de outros fenômenos análogos aos considerados tipicamente quânticos, tais como "tunelamento" e o perfil de probabilidade de uma partícula confinada ser encontrada em uma dada posição 31. Por essas analogias, esses fenômenos despertaram um renovado interesse na teoria de de Broglie bem como debates até onde essa analogia pode nos levar [32 36].

Ressaltamos que existe um limite para as semelhanças, determinado, entre outros pontos, pela possibilidade da existência de elementos incógnitos no processo quântico bem como pela própria escala do processo. No caso do fenômeno de difração de uma gota errante "livre", o tamanho das gotas tem ordem de grandeza comparável ao tamanho das fendas, do comprimento da sua onda piloto e da distância até o anteparo. A velocidade de propagação da gota também é comparável à velocidade que ela quica. Nada disso parece ser equivalente no regime atômico. Essa diferença leva a ter no sistema observado uma dominância da interação gota erranteanteparo. Assim, surgem diferenças tal como existir um limite para o número de picos demonstrado no padrão de interferência nesse regime macroscópico, sugerindo "que a função de distribuição de probabilidade que surge para as [gotas] errantes que passam por uma fenda única ou dupla geralmente terá três picos dominantes" [37. p. 1151]. De qualquer maneira "destacamos que nossos resultados não fecham a porta para a busca de difração e interferência das [gotas] errantes, apenas para as condições de contorno consideradas aqui, para o qual o comportamento do sistema é dominado pelas interações gota errante-anteparo" [37, p. 1152]. Além desse último artigo, vale a pena destacar outros trabalhos também de John W. M. Bush e colaboradores que têm se debruçado sobre essa analogia de maneira meticulosa, tal como o Hydrodynamic quantum field theory: the free particle e o Hydrodynamic quantum field theory: The onset of particle motion and the form of the pilot wave [38, 39, a ponto de estabelecerem um modelo hidrodinâmico para a spintrônica em Emergent order in hydrodynamic spin lattices, observando uma histerese na transição de antiferromagnético para ferromagnético [40].

\section{Tradução}

Segue a tradução. Os termos entre [colchetes] são nossos. Também, no lugar de virgulas, adicionamos travessão (-) para organizar melhor o texto, principalmente quando isso acontece muito - existe uma explicação dentro de explicação e não queremos mudar a pontuação final.

[p. 01]

\section{A Termodinâmica "Oculta" das Partículas}

\author{
por
}

\section{Louis de BROGLIE}

RESUMO. - O autor apresenta uma visão do conjunto de esforços que fez desde 1951 a fim de obter uma imagem clara da dualidade onda-partícula. Retomando as ideias desenvolvidas entre 1926-1927 sob o nome de "teoria da solução dupla", ele primeiro considerou a partícula como um ponto de alta concentração localizada no seio de um campo ondulatório e se deslocando seguindo as leis de uma certa "Dinâmica de Condução" [1] Então, reconheceu a necessidade de completar essa imagem, superpondo ao movimento definido por essa Dinâmica ${ }^{2}$ um tipo de agitação térmica aleatória, o que seria devido à interação constante de qualquer partícula com algum tipo de termostato oculto (meio subquântico de Bohm-Vigier) ${ }^{3}$ Isso o levou recentemente a desenvolver uma "Termodinâmica da partícula isolada" [sobre] a qual expõe os princípios fundamentais e algumas aplicações.

A Interpretação da Mecânica Ondulatória. - Fez quarenta anos ao fim do verão de $19634^{4}$ que me apareceu a

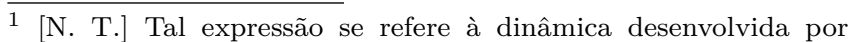
de Broglie para tratar da onda piloto. O substantivo "guidage" do sentido literal significa "processo de impor uma trajetória", no sentido de conduzir algo para algum lugar 41. De Broglie, por exemplo, escreve: "On conçoit alors l'onde continue comme guidant le mouvement de la particule. C'est une onde pilote" [12 p. 241], isto é, "Concebe-se então a onda contínua como guiando/conduzindo o movimento da partícula. Esta é uma onda piloto", os grifos são nossos. Assim, estamos traduzindo a expressão francesa "Dynamique du guidage" como "Dinâmica de Condução" ao invés de "Dinâmica do Guia / do guiante", para destacar essa característica.

2 [N. T.] Parece-nos que de Broglie escreve este nome em maiúscula para deixar claro que não trata de uma dinâmica qualquer, mas a sua Dinâmica de Condução.

3 [N. T.] Em 1954, Bohm e Vigier [16] propõem um modelo para conduzir à interpretação determinista da Mecânica Quântica. Nesse trabalho, eles propõem que, [16, p. 208], "Uma vez que o fluido de Madelung está sendo considerado algum tipo de fluido fisicamente real, é, portanto, bastante natural supor que ele também sofre flutuações mais ou menos aleatórias em seus movimentos". Assim, tomam uma interpretação da hidrodinâmica de Madelung de forma realista.

4 [N. T.] O autor se refere ao seu artigo Ondes et Quanta 6 que escreveu em resposta ao artigo Actions mécaniques à hérédité discuntinue par propagation; essai de la théorie dynamique de l'atome á quanta de 1919 por Marcel Brillouin [42. 
necessidade de estender a todas as partículas o duplo aspecto ondulatório e corpuscular que Einstein, em 1905, nos revelara para a luz na sua teoria dos quanta de luz ${ }^{5}$

Como podemos ver muito claramente, ao reler minha tese defendida no final de $1924{ }^{6}$ cuja reedição acaba de ser concluída, meu objetivo era obter uma imagem sintética em que o corpúsculo, sempre considerado um objeto pequeno e localizado, se deslocando em geral pelo espaço ao longo do tempo, seria incorporado a uma onda de natureza física, de tal maneira que seu movimento esteja ligado à propagação da onda.

Uma das observações essenciais a partir da qual comecei e que nunca

foi mencionada hoje em livros sobre mecânica quântica é a diferença entre a transformação relativística da frequência de uma onda e a da frequência de um relógio. É sabido que, se a frequência de um relógio considerado em seu próprio sistema é $\nu_{0}$ a frequência que atribui a ele um observador que o vê passar com a velocidade $v=\beta c$ é $\nu_{c}=\nu_{0} \sqrt{1-\beta^{2}}$ isso é o que chamamos de fenômeno de "desaceleração dos relógios" por seu movimento 7 Pelo contrário, se uma onda, em um determinado sistema de referência é uma onda estacionária de frequência $\nu_{0}$, essa onda observada em um sistema de referência se movendo com velocidade $v=\beta c$ em relação ao primeiro, aparece como uma onda progressiva propagando-se na direção do movimento relativo com a frequência $\frac{\nu_{c}}{\sqrt{1-\beta^{2}}}$ e com velocidade de fase $V=\frac{c}{\beta}=\frac{c^{2}}{v}$. Se atribuímos ao corpúsculo - como sugerido pela relação fundamental do quantum $W=h \nu$ - uma frequência interna $\nu_{0}=\frac{m_{0} c^{2}}{h} \mathrm{e}$, se admitirmos que no referencial próprio do corpúsculo, a onda associada a ele é uma onda estacionária de frequência $\nu_{0}$, todas as fórmulas fundamentais da Mecânica das Ondas, especialmente a famosa fórmula $\lambda=\frac{h}{p}$, onde $p$ é [o módulo da] a quantidade de movimento do corpúsculo ${ }^{8}$ podem ser deduzidas imediatamente das observações anteriores.

Como eu considerava o corpúsculo constantemente localizado na onda, vi a seguinte consequência: o movimento do corpúsculo é tal que garante a concordância permanente da fase da onda viajante que o envolve, com a fase interna do corpúsculo considerado um pequeno relógio. Esta relação é verificada imediatamente no caso simples de um corpúsculo em movimento uniforme acompanhado de uma onda plana monocromática que estudei principalmente na minha tese.

\footnotetext{
5 [N. T.] On a heuristic point of view concerning the production and transformation of light [5].

6 [N. T.] Recherches sur la théorie des quanta 8] e 43 .

7 [N. T.] Também conhecida como equação da "dilatação do tempo". Chamamos a atenção que as duas nomenclaturas não são equivalentes filosoficamente. Uma atribui o fenômeno à mudança da matéria (relógio) em movimento, a outra entende a grandeza física como uma "substância" - isto é, independente da matéria e com a mesma realidade ontológica (ou mais primitiva) - que pode ser dilatada. No artigo Clock rates in a Machian universe Thomas Erwin Phipps, Jr. (1925-2016) obtém a expressão para a "desaceleração do relógio" a partir do potencial gravitacional de Schröndinger como resultado da interação da matéria distante com um oscilador harmônico em movimento relativo 44 .

8 [N. T.] Optamos por manter a nomenclatura francesa quantidade de movimento para a grandeza $\vec{p}=m \vec{v}$ ao invés da norteamericana momento linear, uma vez que as duas maneiras existem na língua portuguesa.
}

Depois da minha tese, aprofundando essa ideia, fui levado a pensar que quando a onda tem a forma geral

$$
\psi=a(x, y, z, t) e^{\frac{2 \pi i}{h} \varphi(x, y, z, t)}
$$

onde $a$ e $\varphi$ são reais, a concordância da fase entre o corpúsculo e sua onda exigem que a velocidade do corpúsculo em cada ponto de sua trajetória seja fornecido por

$$
\vec{v}=-\frac{1}{m} \overrightarrow{\operatorname{grad}} \varphi
$$

Esta concepção se juntou àquela que na mesma época desenvolvia Madelung, o qual comparou a propagação da onda $\Psi$ da Mecânica Ondulatória ao fluxo de um fluido fictício de densidade $\rho=|\psi|^{2}$ e velocidade

$$
\vec{v}=-\frac{1}{m} \overrightarrow{\operatorname{grad}} \varphi
$$

Com a imagem hidrodinâmica de Madelung, minha hipótese sobre o movimento do corpúsculo se expressava dizendo que a trajetória do corpúsculo coincide com uma das linhas de corrente do fluido hidrodinâmico de Madelung. Chegavase ali, portanto, a considerar a propagação da onda como impondo um determinado movimento ao corpúsculo: é isso que eu a chamei de "teoria da onda piloto".

Fui em seguida levado para além desse primeiro ponto de vista. Na minha opinião, não bastava superpor o corpúsculo à onda, forçando-o a ser guiado pela propagação dela: era preciso representar o corpúsculo como incorporado à onda, como fazendo parte de sua estrutura. Fui assim conduzido ao que chamei de "a teoria da solução dupla": ela admite que a onda real não é homogênea, que envolve uma região muito pequena de alta concentração do campo que constitui o corpúsculo no sentido estrito da palavra, mas que - fora essa região muito pequena - essa onda coincide substancialmente com a onda homogênea projetada pela Mecânica Ondulatória usual. Eu então exibi as primeiras bases dessa nova concepção em um artigo no Journal de Physique em julho de $19277^{9}$

Infelizmente, essa tentativa - na qual eu ainda não introduzira a ideia de um caráter não linear da equação de onda da onda real - se deparava com muitas dificuldades. Já expus várias vezes, em outro lugar, como - em seguida ao Conselho Solvay de outubro de 1927 - fui levado a abandonar essa tentativa e me render, pelo menos provisoriamente, à interpretação da Escola de Copenhague, mas ao longo dos anos que se seguiram sempre mantive um modo de exposição muito mais "objetivo" do que aqueles que se usam cada vez mais, para não me afastar muito de minhas intuições primitivas. Em 1951 - depois de ter ministrado nos anos anteriores cursos sobre a interpretação da Mecânica Ondulatória onde fui levado a revisar as objeções levantadas por pensadores como Einstein, Schrödinger e outros contra a interpretação usual - eu estava em um estado de espírito favorável para um retorno às minhas antigas concepções:

\footnotetext{
9 Ao procurar pelo referido artigo no Journal de Physique, não encontramos nenhum no mês de julho de 1927 (Volume 8 / Numéro 7 (juillet 1927)) de autoria de de Broglie. Seus artigos desse ano nessa revista são: L'univers à cinq dimensions et la mécanique ondulatoire (fevereiro) [45, e La mécanique ondulatoire et la structure atomique de la matière et du rayonnement (maio) [12. Provavelmente deve estar se referindo a este último.
} 
os trabalhos do Sr. David Bohm, dos quais eu então tive conhecimento e minhas longas conversas sobre este problema com o Sr. Jean-Pierre Vigier

\section{[p. 04]}

me levaram a adotar novamente a teoria da solução dupla, introduzindo a ideia de não linearidade.

Não posso desenvolver aqui o progresso que se alcançou nesses últimos anos pela interpretação da Mecânica Ondulatória pela teoria da solução dupla. É possível seguir o desenvolvimento progressivo, dirigindo-se às duas obras que publiquei pela Gauthier-Villars em 1956 e 1957 e a um artigo publicado no Journal de Physique em dezembro 1960 10 Acabo de publicar, também na Gauthier-Villars, um volume dedicado à crítica minuciosa de uma série de pequenas interpretações errôneas que me parecem ter contribuído para orientar a Física Quântica de uma maneira ruim ${ }^{11}$ Não quero esquecer de apontar a ajuda contínua que o Sr. Andrade e Silva trouxe para mim em meu trabalho durante estes últimos anos, pela delicadeza de suas análises, principalmente na elaboração do meu último livro ${ }^{12}$

Superposição ao movimento regular da " condução" de um movimento aleatório. - [Como] vimos na teoria da solução dupla (ou da onda piloto), determina-se o movimento do corpúsculo no seio de sua onda escrita sob a forma $a e^{\frac{2 \pi i}{h} \varphi}$ admitindo que sua velocidade esteja dada pela fórmula de condução:

$$
\vec{v}=-\frac{1}{m} \overrightarrow{\operatorname{grad}} \varphi
$$

sendo $m$ a massa do corpúsculo. Esta forma da fórmula de condução só é válida na Mecânica Ondulatória não relativística correspondente à equação de propagação de Schrödinger. Na Mecânica Ondulatória relativística correspondente à equação de propagação de Klein-Gordon, a fórmula de condução para uma partícula de carga elétrica $\varepsilon$ colocada em um campo eletromagnético derivado de um potencial escalar $V$ e um potencial vetor $\vec{A}$ assume a forma

$$
\vec{v}=-c^{2} \frac{\overrightarrow{\operatorname{grad}} \varphi+\frac{\varepsilon}{c} \vec{A}}{\frac{\partial \varphi}{\partial t}-\varepsilon V}
$$

o qual, na aproximação newtoniana, reduz-se bem à forma (1). No caso de partículas com spin (por exemplo,

\footnotetext{
$\overline{10}$ [N. T.] O autor se refere aos livros Une tentative d'interpretation causale et non linéaire de la Mécanique ondulatoire: la théorie de la double solution 46] e La théorie de la Mesure Mécanique ondulatoire [47. Procuramos, mas não há um artigo publicado em dezembro de 1960 por de Broglie no Journal de Physique, e sim em dezembro de 1959, intitulado L'Interprétation de la Mécanique Ondulatoire [17. Acreditamos que o autor se refira a este último pois também consta nas referências originais deste artigo.

11 [N. T.] Étude critique des bases de l'interprétation actuelle de la Mécanique ondulatoire 48.

12 [N. T.] João Andrade e Silva (1928-2017), catedrático português e um dos grandes apoiadores de de Broglie. A seu respeito Georges Lochak, então presidente da Fondation Louis de Broglie, escreveu que "Joao Andrade e Silva era um desses intelectuais portugueses que, não desejando viver no Portugal de Salazar, se exilou na França com sua família e permaneceria uma quinzena de anos trabalhando no instituto Henri Poincaré no grupo de pesquisa dirigido por Louis de Broglie. Ele fez sua tese sob a direção deste último: A Teoria dos sistemas de partículas na interpretação causal da Mecânica Ondulatória" 49.
}

para o elétron de Dirac), se deduzirá a fórmula de condução escrevendo sempre que a partícula segue uma das linhas de corrente do escoamento hidrodinâmico correspondente às equações de propagação.

Penso que o fenômeno de condução da partícula pelo campo (ondulatório) circundante resulta, como na teoria da relatividade geral, do fato de que as equações de campo são não lineares e que esta não linearidade, que se manifesta quase unicamente na região corpuscular, restitui o movimento da partícula solidária à propagação da onda que a rodeia. Usando um método análogo àquele que Georges Darmois empregou outrora para justificar o "postulado das geodésicas" na teoria da Relatividade Geral e que foi desenvolvido pelo senhor Lichnerowicz ${ }^{13}$ pode-se representar aproximadamente o corpúsculo como uma singularidade do campo ondulatório e mostrar que, por razões de continuidade, a singularidade em seu movimento deve permanecer constantemente aprisionada ao interior de um tubo infinitamente delgado das linhas de corrente do campo externo ${ }^{14}$ Mas não posso insistir aqui sobre essa justificativa da fórmula de condução.

Mas há uma consequência da fórmula de condução, sobre a qual devo insistir. Mesmo quando uma partícula não está sujeita a nenhum campo exterior, se a onda circundante não for uma onda substancialmente plana e monocromática (ou seja, se esta onda deve ser representada por uma superposição de ondas planas monocromáticas), o movimento que lhe é imposto pela fórmula de condução não é retilíneo e uniforme. Isso me fez pensar já em 1927 que o corpúsculo estava sofrendo, a partir da onda circundante, uma força que encurvava sua trajetória: esta "força quântica" seria igual ao gradiente alterado em sinal [com sinal oposto] de um potencial quântico (Q) cuja expressão na Mecânica Ondulatória não relativística é escrita

$$
\mathrm{Q}=-\frac{h^{2}}{8 \pi^{2} m} \frac{\Delta a}{a} .
$$

Mas, na Mecânica Ondulatória relativística, deve-se considerar que a força quântica é igual ao gradiente alterado em sinal [com sinal oposto] da grandeza

$$
\mathrm{M}_{0} c^{2}=\sqrt{m_{0}^{2} c^{4}+\frac{h^{2} c^{2}}{4 \pi^{2}} \frac{\square a}{a}}\left(\square=\frac{1}{c^{2}} \frac{\partial^{2}}{\partial t^{2}}-\nabla^{2}\right) .
$$

Como o potencial quântico $\mathrm{Q}$ é definido apenas até uma constante, nós podemos escrever

$$
\mathrm{Q}=\mathrm{M}_{0} c^{2}-m_{0} c^{2}
$$

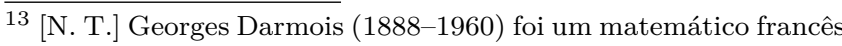
e autor do livro Les équations de la gravitation einsteinienne 50 . Este foi orientador de doutorado de André Lichnerowicz (19151998), também matemático francês, cujo foco das pesquisas foram especialmente em Física Matemática e Relatividade Geral.

14 [N. T.] Por usar o termo "linhas de corrente de campo" observase que de Broglie guarda a concepção hidrodinâmica do que é chamado hoje por " linhas de campo". Isso parece ser natural, uma vez que as equações da eletrodinâmica usadas por MaxwellLorentz partem dessa analogia. Sendo assim, neste caso, percebe-se que a visão de de Broglie do campo eletromagnético se aproxima da visão continuista desses pensadores, onde existe uma entidade que circunda a matéria ponderável, não só como um sujeito de interação, mas como fonte e meio dela, obedecendo uma analogia com a dinâmica dos fluidos. 
A grandeza $\mathrm{M}_{0}$, que é uma função geral de $x, y, z$ e $t$ e que se reduz, quando Q é nulo, à massa própria constante $m_{0}$ usualmente atribuída à partícula, pode ser chamada [como] a "massa própria variável" da partícula: Ela vai representar um grande papel naquilo que segue. É, ademais, fácil verificar

[p. 06]

que a definição (5), levando em consideração o valor (4) de $\mathrm{M}_{0}$, se reduz à aproximação newtoniana na definição (3).

A teoria de condução que usa as fórmulas que acabamos de especificar impõe à partícula um movimento bem determinado quando se fornece sua posição na onda em um instante inicial dado. Esse era o ponto de vista que eu havia adotado primitivamente em 1927 e ao qual ainda me mantive quando retornei à teoria da solução dupla, há uma dúzia de anos. Mas logo me pareceu com uma evidência crescente que essa concepção não era suficiente e que havia de superpor ao movimento regular, e de certa forma "médio" da partícula que definiu a fórmula de condução, um tipo de movimento "browniano" de caráter aleatório.

Para dar conta da necessidade de introduzir esse novo elemento na teoria, é preciso lembrar que, se $\rho$ denota a densidade do fluido fictício na imagem hidrodinâmica de propagação de ondas - densidade que, na Mecânica Ondulatória não relativística, é igual à $|\psi(x, y, z, t)|^{2}-[$ assim] se é levado a considerar que a quantidade $\rho d \tau$ dá a probabilidade da presença da partícula no tempo $t$ dentro do elemento de volume $d \tau$ do espaço físico. Para tentar justificar esse resultado na teoria da solução dupla, pode-se partir da equação de continuidade do fluido fictício

$$
\frac{\partial \rho}{\partial t}+\operatorname{div}(\rho \vec{v})=0
$$

equação na qual $\vec{v}$ é precisamente a velocidade de condução. Ao considerar o movimento de um elemento de volume $d \tau$ que sempre contém o mesmos elementos do fluido, vê-se que a equação (6), a qual, com uma notação bem conhecida na hidrodinâmica, pode ser escrits ${ }^{15}$

$$
\frac{\mathrm{D}}{\mathrm{D} t}(\rho d \tau)=0
$$

expressa a conservação ao longo do tempo do produto $\rho d \tau$. Assim como na Mecânica Estatística clássica, o teorema de Liouville - que é expresso por $\frac{\mathrm{D}}{\mathrm{D} t} d \tau=0$ - torna muito verossímil a priori que a probabilidade da presença do ponto representativo de um sistema dentro do elemento de $d \tau$ no espaço de fase é proporcional ao tamanho desse elemento, igualmente aqui a equação $(7)$ torna a priori muito verossímil que a probabilidade da presença da partícula dentro do elemento $d \tau$ do espaço físico é proporcional a $\rho d \tau$. Há uma grande analogia entre os dois problemas com, no entanto, esta diferença: que na Mecânica Estatística se considera o movimento de um ponto representativo no espaço de fase, enquanto

15 [N. T.] A equação de continuidade na forma integral é

$$
\frac{d q}{d t}+\oiint \vec{j} \cdot d \vec{S}=0
$$

No nosso caso $q=\rho d \tau$ e $\vec{j}=\rho \vec{v}$. O autor acaba usando a letra D maiúscula para denotar a diferencial total e mantivemos assim. Por considerar "o movimento de um elemento de volume $d \tau$ que sempre contém o mesmos elementos do fluido" a integral na superfície fechada é zero. aqui nós consideramos o movimento da partícula no espaço físico.

A analogia entre os dois problemas traz uma analogia nas dificuldades encontradas quando examinamos com cuidado a demonstração do resultado desejado. Em um caso como no outro, a validade do resultado exigiria que o elemento, durante seu movimento, varresse a totalidade do espaço (espaço de fase em um caso, espaço físico no outro) que o é acessível. Sabe-se que, para a justificar essa hipótese, somo levados [a ela] na Mecânica Estatística seja para tentar demonstrar um teorema de ergodicidade, seja para introduzir com Boltzmann uma hipótese de "caos molecular". No problema que nos preocupa, é este segundo caminho que seguiram os senhores David Bohm e Jean-Pierre Vigier quando introduziram em 1954, em um artigo na Physical Review a ideia do "meio subquântico" ${ }^{16}$ ideia cuja importância rapidamente me pareceu capital.

De acordo com os senhores Bohm e Vigier, existiria um meio oculto, correspondente a um nível da realidade física mais profundo do que o nível quântico ou microfísico, meio com o qual todas as partículas no nível microfísico estariam interagindo constantemente. A complexidade desse meio, do qual me parece prematuro querer especificar exatamente a natureza, terá por consequência provocar o caráter puramente aleatório das perturbações que sua ação impõe ao movimento das partículas microfísicas.

Sob a influência dessas contínuas perturbações aleatórias que lhe transmitem o "meio subquântico", a partícula, em vez de seguir regularmente uma das trajetórias definidas pela lei de condução, constantemente salta de uma dessas trajetórias para outra, percorrendo assim em muito pouco tempo um número muito grande de seções dessas trajetórias e, se a onda permanece confinada a uma região finita do espaço, essa trajetória em zigue-zague é forçada a explorar completamente toda essa região. Pode-se então justificar a afirmação de que a probabilidade da presença da partícula em um elemento de volume $d \tau$ do espaço físico deve ser igual a $|\Psi|^{2} d \tau$. É isso que os Srs. Bohm e Vigier fazem em suas memórias: eles mostraram que a distribuição de probabilidade em $|\Psi|^{2}$ deve, portanto, ser estabelecida muito rapidamente. O Sr. Andrade e Silva, que refletiu muito sobre o assunto, vinculou o sucesso dessa prova às propriedades das "cadeias de Markhov"17

Sem insistir sobre essas demonstrações, gostaria de oferecer uma imagem que aclará o significado do que precede. Consideremos o escoamento de um fluido: a hidrodinâmica define a trajetória de uma molécula desse fluido, a qual, em cada um de seus pontos, é tangente à "linha de corrente" que passa por este ponto e que, no caso de um movimento permanente, coincide com

\section{[p. 08]}

uma das linhas de corrente. Ora, a trajetória assim definida é apenas uma trajetória "ideal" ou "média", que só seria efetivamente descrita se a molécula não sofresse qualquer perturbação. Mas isso nunca é assim: o fluido nunca estando

16 [N. T.] Como citado na introdução, o artigo 16.

17 [N. T.] Cadeias de Markhov é um modelo usado em Física Estatística para descrever sistemas em que a probabilidade de se obter um estado em determinado passo depende apenas do estado no passo anterior. 
em zero absoluto, suas moléculas são animadas com uma agitação térmica devido aos seus incessantes choques mútuos e por este motivo, cada uma delas passa constantemente de uma trajetória teórica para outra. Isto é porque as moléculas descrevem assim uma trajetória continuamente em ziguezague que seja permitida - se $\rho$ denota a densidade do fluido considerar a quantidade $\rho d \tau$ como medindo a probabilidade da presença de uma molécula dado no elemento $d \tau$.

Para acabar de mostrar a necessidade de introduzir na teoria as pertubações Bohm-Vigier de origem subquântica, considerarei o caso de um átomo de hidrogênio em um estado estacionário de energia $\mathrm{E}$, onde a função de onda está na forma

$$
\psi=a(x, y, z) e^{\frac{2 \pi i}{h} \mathrm{E} t} .
$$

A fórmula de condução, então, nos dá $\vec{v}=0$ : isto significa que o elétron está estacionário em um ponto do átomo e é fácil verificar que, neste caso, a força de Coulomb que o núcleo exerce sobre o elétron é exatamente equilibrado pela força quântica. Mas, se o elétron estava assim imóvel, como poderíamos entender que a probabilidade do elétron em qualquer ponto do átomo é dado pela expressão

$$
|\psi|^{2}=|a(x, y, z)|^{2} ?
$$

Tudo pode se explicar ao admitir que o elétron, embora permaneça "a princípio" imóvel, salta constantemente de uma posição para outra, sob a influência de distúrbios contínuos de origem subquântica. E esse exemplo demonstra, de forma marcante, a necessidade dessas perturbações terem lugar na teoria da solução dupla, ou seja, de superpor ao movimento regular da partícula prevista pela teoria de condução um movimento browniano de caráter aleatório.

Introdução da ideia de uma Termodinâmica oculta. - Sabe-se que ao final do século passado, graças principalmente aos trabalhos de Boltzmann e Gibbs, desenvolveuse uma interpretação estatística da Termodinâmica cujo sucesso foi, no fim das contas, total. Mas, no mesmo período, alguns autores, notadamente Helmholtz e o próprio Boltzmann, procuraram, com algum sucesso, fazer analogias entre as grandezas introduzidas pela Termodinâmica e certas grandezas da

Mecânica Clássica sem qualquer intervenção de considerações estatísticas. Essas tentativas interessantes foram posteriormente esquecidas e dificilmente foram usadas, exceto na teoria dos invariantes adiabáticos (Léon Brillouin).

Durante os anos de 1946-1948, repeti nas notas aos Comptes Rendus de l'Académie des Sciences (Informes da Academia de Ciências), por um curso do Instituto HenriPoincaré e em um artigo no Cahiers de Physique (Cadernos de Física), o exame desses antigos trabalhos e, naturalmente, tratei de aproximá-los das concepções da Mecânica Ondulatória. Fui então levado a definir para uma partícula em movimento com velocidade $\beta c$ uma temperatura $\mathrm{T}$ ligada à frequência cíclica da parte interna da partícula que, como vimos, é dada por

$$
\nu_{c}=\nu_{0} \sqrt{1-\beta^{2}}=\frac{m_{o} c^{2}}{h} \sqrt{1-\beta^{2}}
$$

pela relação

$$
k \mathrm{~T}=h \nu_{c}
$$

onde $k$ é a constante de Boltzmann. Eu também fui levado a definir uma entropia a partir da ação da partícula no sentido da mecânica. Essas analogias não me davam [a sensação de] completa satisfação, mas elas me pareciam bastante curiosas. Igualmente, terminara meu artigo no Cahiers de Physique de janeiro de 1948, escrevendo esta frase marcada por uma certa hesitação: "Há o início de uma termodinâmica do ponto material que se poderá procurar a desenvolver no âmbito da Mecânica Ondulatória: é bastante difícil dizer aonde esse caminho poderá conduzir e nós nos contentaremos em ter indicado o ponto de partida".

De onde provinha a hesitação que essa frase deixava transparecer? Ela vinha de fato que, convencido de que a termodinâmica é essencialmente de origem estatística e não faz sentido a não ser para sistemas muito complexos, eu não podia compreender como podia existir uma termodinâmica válida para um partícula suposta como isolada e é o porque, durante muitos anos, eu renunciei tentar desenvolver uma teoria desse gênero.

Mas, faz dois anos, eu decidi retornar ao estudo de ideias as quais, apesar de tudo, retiveram fortemente a minha atenção. Ora, nessa época, tendo retomado depois de vários anos minhas reflexões sobre a teoria da solução dupla, eu admitia a existência de um meio subquântico. Rapidamente, um traço de luz brotou de meu espírito. Se toda partícula que nos parece como isolada à escalada microscópica pode constantemente trocar de energia e de quantidade de movimento com o meio subquântico, este representa um papel de um "termostato oculto" com o qual a partícula está constantemente em contato energético. Consequentemente, não há mais a priori nenhum

[p. 10]

paradoxo em desejar desenvolver uma Termodinâmica da partícula isolada. Isto é o que tratei de fazer em uma primeira nota aos Comptes Rendus de l'Académie des Sciences em agosto de 1961, depois, de uma maneira que me pareceu bastante satisfatória, em outras duas notas aos Comptes Rendus de l'Académie des Sciences em agosto de $19622^{18}$ $\mathrm{Eu}$ acabo, neste momento, a redaçã ${ }^{19}$ de uma livro onde exporei, como fiz no meu última curso no Instituto HenriPoincaré, durante o inverno de 1961-1962, os princípios desta "Termodinâmica da partícula isolada". Destacarei ademais que essa Termodinâmica sendo aplicável aos conjuntos de partículas em interação que estão todas em contato energético com o termostato escondido o nome de "Termodinâmica oculta das partículas" será talvez preferível ao nome que, por razões evidentes, eu inicialmente adotei.

Mas, antes de expor a você as bases e algumas aplicações dessa nova teoria muito atraente, devo inicialmente lembrar algumas noções de Termodinâmica relativística que são conhecidas faz bastante tempo (trabalhos de Planck e de sua escola por volta de 1910) mas que se ensina raramente nas faculdades 20

18 [N. T.] Nouvelle présentation de la Thermodynamique de la particule isolée 21] e Quelques conséquences de la Thermodynamique de la particule isolée [20.

19 [N. T.] No original está escrito rédúction (redução) ao invés de rédaction (redação) o que nos parece um erro tipográfico. Trocamos para manter a coerência textual.

20 [N. T.] Vale a pena notar a mudança de tom discursivo do autor, que aqui trata direto com o leitor. 
Lembrete de algumas noções de Termodinâmica relativística. $\sqrt{21}$ - Na Termodinâmica relativística, demonstra-se que, se um corpo considerado no seu sistema próprio possui uma temperatura $T_{0}$ e contém uma quantidade de calor $Q_{0}$, para um observador que o vê passar com uma velocidade $\beta c$ ele possui uma temperatura $\mathrm{T}$ e contém uma quantidade de calor Q que são dadas pelas fórmulas:

$$
\mathrm{T}=\mathrm{T}_{0} \sqrt{1-\beta^{2}} ; \quad \mathrm{Q}=\mathrm{Q}_{0} \sqrt{1-\beta^{2}} .
$$

Também demonstramos, e isto resulta quase imediatamente das fórmulas em (8), que a entropia é um invariante relativístico, ou seja, $\mathrm{S}_{0}=\mathrm{S}$.

Antes de ir mais adiante, faremos uma convenção de notação que nos será bastante útil no que se segue. Se A é uma grandeza cujo valor depende da massa própria $\mathrm{M}_{0}$ de um corpo e também de outros parâmetros tais como a velocidade ou a posição desse corpo, nós denotaremos por $[\delta \mathrm{A}]_{\mathrm{M}_{0}}$ a pequena variação que $\mathrm{A}$ experimenta quando, mantendo $\mathrm{M}_{0}$ constante, faz-se variar levemente os outros parâmetros, e por $\delta_{\mathrm{M}_{0}} \mathrm{~A}$ a pequena variação que experimenta A quando se faz variar levemente $\mathrm{M}_{0}[\mathrm{e}]$ os outros parâmetros permanecendo constantes. Isto posto, consideremos um corpo no seu sistema próprio: sua massa própria será $\mathrm{M}_{0}$ e, de acordo com o princípio da inércia da energia, sua energia interna será $\mathrm{W}_{0}=\mathrm{M}_{0} c^{2}$ Se sua massa própria sofre uma ligeira variação $\delta M_{0}$, sua energia interna variará de $\delta \mathrm{W}_{0}=\delta \mathrm{M}_{0} c^{2}$. Isto pode acontecer apenas se o corpo recebeu ou cedeu a energia $\delta \mathrm{W}_{0}$ e, como

\section{[p. 11]}

a energia interna é a energia armazenada no interior dos corpos, deve-se considerar a quantidade $\delta \mathrm{M}_{0} c^{2}$ como uma quantidade de calor $\delta Q_{0}{ }^{23}$ Então, para um observador que vê o corpo passar com a velocidade $\beta c$ a quantidade de calor recebido ou cedido pelo corpo será

$$
\delta \mathrm{Q}=\delta \mathrm{Q}_{0} \sqrt{1-\beta^{2}}=\delta \mathrm{M}_{0} c^{2} \sqrt{1-\beta^{2}} .
$$

Ora, como é bem conhecido na dinâmica relativística, para esse observador a função de Lagrange será

$$
\mathcal{L}=-\mathrm{M}_{0} c^{2} \sqrt{1-\beta^{2}}+\cdots,
$$

[onde] os termos não escritos não dependem de $\mathrm{M}_{0}$. Temos, então:

$$
\delta \mathrm{Q}=-\delta_{\mathrm{M}_{0}} \mathcal{L}
$$

\footnotetext{
21 [N. T.] Uma discussão mais detalhada dos conceitos de termodinâmica relativística pode ser encontrada no livro de de Broglie [22]. Alternativamente, uma apresentação detalhada e didática pode ser encontrada em 51.

22 [N. T.] Essa expressão também é chamada equação da equivalência massa e energia. Pode-se ter uma diferença filosófica na adoção desses nomes. No primeiro se estabelece que "energia" apresenta qualidades inerciais equivalentes à "massa". No outro a equivalência é total, como se uma grandeza se transformasse na outra. Ao que parece, de Broglie adota a segunda posição. Sobre o princípio da inércia da energia ver [52. Recomendamos também os artigos em português 5356 .

23 [N. T.] Interpretando a equação como uma equivalência completa entre massa e energia, isso poderia levar à medição da variação da força gravitacional sobre um objeto em altas temperaturas. Recentemente foi realizada uma nova medição com uma precisão maior que as anteriores, e tal mudança ainda não foi observada [57.
}

É fácil encontrar esta fórmula por outros raciocínios mais completos que darei no livro que preparo. Vou indicar aqui um.

Coloquemo-nos no sistema do observador que vê o corpo passar com a velocidade $\beta c$. Ele pode escrever as duas fórmulas da dinâmica relativística

$$
\mathrm{W}=\frac{\mathrm{M}_{0} c^{2}}{\sqrt{1-\beta^{2}}}, \quad \frac{d}{d t}\left[\frac{\mathrm{M}_{0} v}{\sqrt{1-\beta^{2}}}\right]=f .
$$

A partir da segunda [fórmula], obtemos a seguinte expressão a partir do trabalho recebido pelo corpo durante o tempo $\delta t$ :

$$
d \mathcal{T}=f v \delta t=v \delta \frac{\mathrm{M}_{0} v}{\sqrt{1-\beta^{2}}}
$$

Ao supor a massa própria constante, como se faz habitualmente na dinâmica relativística, verifica-se facilmente que o trabalho em questão tem por valor

$$
[\delta \mathcal{T}]_{\mathrm{M}_{0}}=[\delta \mathrm{W}]_{\mathrm{M}_{0}}
$$

o que é normal. Mas, se a massa própria pode variar, se terá para o trabalho fornecido ao corpo

$$
\delta \mathcal{T}=[\delta \mathcal{T}]_{\mathrm{M}_{0}}+\delta_{\mathrm{M}_{0}} \mathcal{T}=[\delta \mathrm{W}]_{\mathrm{M}_{0}}+\frac{v^{2}}{\sqrt{1-\beta^{2}}} \delta \mathrm{M}_{0} .
$$

Ora, temos também

$$
\delta \mathrm{W}=[\delta \mathrm{W}]_{\mathrm{M}_{0}}+\frac{c^{2}}{\sqrt{1-\beta^{2}}} \delta \mathrm{M}_{0}
$$

e das equações 15 e 16 se obtém

$$
\delta \mathrm{W}=\delta \mathcal{T}+\delta \mathrm{M}_{0} c^{2} \sqrt{1-\beta^{2}} .
$$

Como o princípio de conservação de energia fornece $\delta \mathrm{W}=$ $\delta \mathcal{T}+\delta \mathrm{Q}$, onde $\delta \mathrm{Q}$ é a quantidade de calor recebida pelo corpo, encontramos as fórmulas $(9$ e 11 .

Termodinâmica da partícula isolada ou Termodinâmica oculta das partículas. - Para desenvolver a Termodinâmica da partícula isolada, admitiremos inicialmente que podemos aplicar a uma partícula isolada da escala microfísica a fórmula [ [11]

$$
\delta \mathrm{Q}=-\delta_{\mathrm{M}_{0}} \mathcal{L} .
$$

Além do mais, também admitiremos, de acordo com minhas velhas ideias entre 1946-1948, que a partícula, em contato permanente com o termostato oculto, pode ser considerada como tendo uma temperatura $\mathrm{T}$ definida pela fórmula que possui a covariância relativística desejada:

$$
k \mathrm{~T}=h \nu_{c}=h \nu_{0} \sqrt{1-\beta^{2}}=m_{0} c^{2} \sqrt{1-\beta^{2}}
$$

Definiremos a entropia relacionando-a com o termostato oculto o qual é um sistema muito complexo. Inspirado no método usado no passado por Einstein em seu trabalho sobre as flutuações, escreveremos entropia $\mathrm{S}$ do termostato escondido sob a forma:

$$
\mathrm{S}=\mathrm{S}_{0}+\mathrm{S}\left(\mathrm{M}_{0}\right)
$$

onde $\mathrm{S}_{0}$ é a parte dessa entropia que é independente do valor flutuante da massa própria $\mathrm{M}_{0}$ da partícula, enquanto $\mathrm{S}\left(\mathrm{M}_{0}\right)$ 
é a pequena parte desta entropia que depende do valor de $\mathrm{M}_{0}$. Teremos então

$$
\delta_{\mathrm{M}_{0}} \mathrm{~S}=\delta \mathrm{S}\left(\mathrm{M}_{0}\right)=-\frac{\delta \mathrm{Q}}{\mathrm{T}}=\frac{\delta_{\mathrm{M}_{0}} \mathcal{L}}{\mathrm{T}}
$$

$\mathrm{O}$ sinal - aparecendo na frente de $\delta \mathrm{Q}$ vem do fato de que $\delta \mathrm{Q}$ é o calor cedido pelo termostato escondido na partícula. Usando as fórmulas (10) e (11), nós obtemos

$$
\delta \mathrm{S}\left(\mathrm{M}_{0}\right)=-k \frac{\delta \mathrm{M}_{0}}{m_{0}}
$$

de onde enfim

$$
\mathrm{S}=\mathrm{S}_{0}-k \frac{\mathrm{M}_{0}}{m_{0}}
$$

[é a] fórmula fundamental onde a invariância do segundo número é bem colocada em evidência.

É fácil tirar dessa fórmula uma primeira consequência importante.

Em efeito, de acordo com a fórmula de Boltzmann relacionando entropia com probabilidade, a probabilidade do valor $\mathrm{M}_{0}$ da massa própria flutuante deve ser proporcional a $e^{\frac{\mathrm{S}}{k}}$, ou seja, a $e^{-\frac{\mathrm{M}_{0}}{m_{0}}}$. Conclui-se que o valor médio de $\mathrm{M}_{0}$ para uma partícula fora de qualquer campo de força (clássico ou quântico) é

$$
\overline{\mathrm{M}}_{0}=\frac{\int_{0}^{\infty} \mathrm{M}_{0} e^{-\frac{\mathrm{M}_{0}}{m_{0}}} d \mathrm{M}_{0}}{\int_{0}^{\infty} e^{-\frac{\mathrm{M}_{0}}{m_{0}}} d \mathrm{M}_{0}}=m_{0}
$$

Assim, a massa própria constante $m_{0}$ geralmente atribuída à partícula parece-nos ser o valor médio da verdadeira massa própria $\mathrm{M}_{0}$ instantânea que é flutuante.

Uma outra consequência interessante desta teoria é estabelecer uma ligação entre o princípio da mínima ação e a segunda lei da Termodinâmica. O princípio de ação mínima de Hamilton nos diz que se - em seu movimento natural de acordo com as leis da dinâmica - a partícula parte de um ponto $\mathrm{A}$ ao instante $t_{0}$ para chegar ao ponto $\mathrm{B}$ no instante $t_{1}$, a integral da ação tomada ao longo desse movimento é mínima em comparação com a mesma integral tomada ao longo de qualquer movimento "variado" que levará a partícula do ponto A no instante $t_{0}$, até o ponto B ao instante $t_{1}$. Então se é levado a escrever

$$
\int_{t_{0}}^{t_{1}}[\delta \mathcal{L}]_{\mathrm{M}_{0}} d t=0, \int_{t_{0}}^{t_{1}}\left[\delta^{2} \mathcal{L}\right]_{\mathrm{M}_{0}} d t>0
$$

a primeira e a segunda variações de $\mathcal{L}$ sendo tomadas, mantendo a massa própria $\mathrm{M}_{0}$ constante e igual ao seu valor médio $m_{0}$.

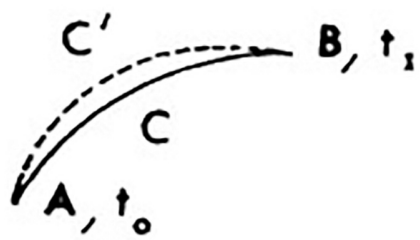

Eu introduzi aqui uma hipótese que me parece ter um significado físico muito interessante.
Sendo ACB a trajetória natural, supus que trajetórias variadas

tais como AC'B não correspondem, como se supõe geralmente, a movimentos fictícios imaginados pelo teórico, mas a movimentos que podem realmente ocorrer quando a própria massa da partícula $\mathrm{M}_{0}$ sofre entre $t_{0}$ e $t_{1}$ uma certa sequência de flutuações. Agora, a trajetória flutuante entre AC'B deve, de acordo com o princípio de Hamilton, ser determinada pela equação

$$
\int_{t_{0}}^{t_{1}} \delta(\mathcal{L}+\delta \mathcal{L}) d t=\int_{t_{0}}^{t_{1}}\left(\delta \mathcal{L}+\delta^{2} \mathcal{L}\right) d t=0 .
$$

Mas, aqui, a massa própria não sendo mais suposta constante, deve-se escrever:

$$
\delta \mathcal{L}=[\delta \mathcal{L}]_{\mathrm{M}_{0}}+\delta_{\mathrm{M}_{0}} \mathcal{L} ; \quad \delta^{2} \mathcal{L}=\left[\delta^{2} \mathcal{L}\right]_{\mathrm{M}_{0}}+\delta_{\mathrm{M}_{0}}^{2} \mathcal{L},
$$

onde $\delta_{\mathrm{M}}^{2} \mathcal{L}$ designa o conjunto de termos que, em $\delta^{2} \mathcal{L}$ dependem da variação de $\mathrm{M}_{0}$. Temos, então, sobre AC'B

$$
\int_{t_{0}}^{t_{1}}\left\{[\delta \mathcal{L}]_{\mathrm{M}_{0}}+\delta_{\mathrm{M}_{0}} \mathcal{L}+\left[\delta^{2} \mathcal{L}\right]_{\mathrm{M}_{0}}+\delta_{\mathrm{M}_{0}}^{2} \mathcal{L}\right\} d t=0 .
$$

Mas a integral do primeiro termo é zero em virtude do princípio de Hamilton e pode-se facilmente verificar que o quarto termo é negligenciável em relação aos outros. Por fim, resta, levando-se em consideração (23),

$$
-\int_{t_{0}}^{t_{1}} \delta_{\mathrm{M}_{0}} \mathcal{L} d t=-\left(t_{1}-t_{0}\right) \overline{\delta_{M_{0}} \mathcal{L}}=\int_{t_{0}}^{t_{1}}\left[\delta^{2} \mathcal{L}\right]_{\mathrm{M}_{0}} d t>0,
$$

sendo $\overline{\delta_{\mathrm{M}_{0}} L}$ [o resultado de] uma média temporal entre $t_{0}$ e $t_{1}$. Então, como $t_{1}-t_{0}$ é positivo e que $-\delta_{\mathrm{M}_{0}} L$ é o calor cedido pelo termostato oculto para a partícula, vê-se que na média temporal essa quantidade de calor, que é nula sobre a trajetória natural, é positiva na trajetória flutuante. Em outras palavras, a entropia $\mathrm{S}$ diminui em média quando se passa de ACB para AC'B. A entropia é, portanto, máxima na trajetória natural em relação a flutuações sujeitas às condições de variação hamiltoniana. A trajetória natural é, portanto, mais provável do que as trajetórias flutuantes. Assim, aparece uma ligação muito curiosa entre o princípio da mínima ação e a segunda lei da Termodinâmica quando se coloca em nosso quadro de ideias ${ }^{24}$

A situação de uma partícula em contato energético permanente com um termostato oculto, apresenta uma certa analogia com aquela de um grânulo visível ao microscópio óptico e submetido à ação da gravidade, que se encontra em suspensão em um fluido cujas moléculas constituem um termostato oculto. No momento onde Jean Perrin seguia com suas suas célebres experiências sobre grânulos deste

24 [N. A.] Em termos de imagens, pode-se dizer que a trajetória natural segue o talvegue [caminho mais fundo] de um vale de negentropia [entropia negativa]. Para o caso onde existe entre os pontos A e B um "hipocentro cinético" [ou foco cinético] com relação a A, ver C. R. Acad. Sc. [Comptes Rendus de l'Académie des Sciences] t. 257, 1963, p. 1822. 
tipo, teorias termodinâmicas aprofundadas sobre flutuações na altitude dos grânulos no fluido foram desenvolvidas por Smoluchowsky, notadamente com o método de Einstein, e são muito interessantes de comparar com a nossa teoria ${ }^{25}$

Transições quânticas e a "prerrogativa" dos estados monocromáticos. - Desde a teoria do átomo de Bohr em 1913, se atribui às transições quânticas - as quais passam um sistema estacionário de um estado para um outro um caráter que se poder qualificar de místico ${ }^{26}$ Renunciase, com efeito, a se fazer qualquer imagem [a respeito] e o sr. Bohr não hesitou em afirmar que elas "transcendem" toda descrição em termos de espaço e de tempo. Isto que levara Schrödinger a dizer ironicamente que, na teoria atual, se descrevia minuciosamente os estados estacionários onde nada acontece, mas se recusava a dizer algo das transições quânticas onde alguma coisa acontece.

A ideia introduzida pela teoria da solução dupla que a Mecânica Ondulatória em última análise deve repousar sobre equações não lineares permite pensar que, se as transições quânticas escapam à teoria usual, é que elas constituem processos essencialmente não lineares. Elas seriam processos transitórios muito breves, análogos a estes que já se encontrou em várias teorias não lineares na Mecânica e em Física quando há transição repentina de um ciclo limite a um outro. Essa ideia muito atraente já fora considerada, faz alguns anos, pelos srs. Cap e Destouches e foi retomada ultimamente pelos senhores Fer, Lochak e Andrade e Silva que publicaram notas a esse respeito de grande interesse ${ }^{27}$

Ora, quando os srs. Fer, Lochak e Andrade e Silva souberam de minha primeira nota de agosto de 1961 sobre a Termodinâmica da partícula isolada - depois de justamente eu destacar fortemente que minhas fórmulas deduzidas da relação $d \mathrm{~S}=\frac{d \mathrm{Q}}{\mathrm{T}}$ se aplicam apenas aos fenômenos reversíveis eles me sugeriram que os estados transitórios muito bruscos que eles consideraram poderiam bem ser transformações acompanhadas de um aumento brusco da entropia, e que a passagem de um estado estacionário

\section{[p. 16]}

a um outro poderia bem figurar [comporter] a travessia por um vale de entropia (ou montanha de negentropia).

Durante o último inverno de 1962-1963, fui levado a pensar mais profundamente sobre essas sugestões interessantes. Para

25 [N. T.] Jean Baptiste Perrin (1870-1942) físico francês, recebeu o Prêmio Nobel em 1926 por "pelo seu trabalho a respeito da estrutura descontínua da matéria, e especialmente pela sua descoberta do equilíbrio de sedimentação" 58. Marian Smoluchowski (18721917) foi um físico polaco que estudou o movimento browniano desde 1900 de maneira independente e publicando seus resultados em 1906 sob o título "Sobre a teoria cinética do movimento molecular browniano e suspensões" 59, logo depois do artigo "Sobre o movimento de pequenas partículas suspensas em líquidos estacionários exigido pela teoria cinética molecular do calor" de Einstein. No entanto, ao contrário da afirmação de de Broglie, o biógrafo Teske afirma que Smoluchowski usou um "método diferente" do de Einstein [60, p. 496].

26 [N. T.] Era desconhecido ao autor a existência do modelo planetário atômico de Weber 61, 62, o qual, a partir de sua eletrodinâmica prevê estados permitidos e proibidos de órbitas estacionárias.

27 [N. T.] Refere-se ao físico austríaco Ferdinand Franz Čap (19242016) e as referências 63 64, bem como o físico francês Jean-Louis Destouches (1909-1980) e as referências 65, 66]. Sobre Destouches, vale a pena ler o artigo 67. compreender o caminho do meu pensamento sobre esse assunto, eu partirei da observação em que, na teoria usual, acorda-se uma classe de prerrogativa aos estados que se pode qualificar por "monocromáticos". Especificando o que entendo por isso, de uma parte [são] os estados estacionários dos sistemas quantificados os quais são associados a uma onda estacionária monocromática representada por uma autofunção da hamiltoniana, por outra parte [são] - no caso das partículas em movimento progressivo - os estados associados à grupos de ondas limitadas as quais são equiparáveis na maior parte de sua extensão a uma onda plana monocromática. Essa prerrogativa consiste nisto, que se vê esses estados monocromáticos como normalmente mais inteligíveis que os estados representados por uma superposição de autofunções ou de ondas planas monocromáticas. Desde o início da teoria atômica de Bohr, considera-se o átomo como se encontrando necessariamente sempre em um estado estacionário e quando, mais tarde, se traduziu a teoria de Bohr na linguagem da Mecânica Ondulatória, admitiu-se que os estados representados por superposições de autofunções tinham apenas uma existência muito fugaz e que, em última análise, o átomo era sempre tomado pela observação em um estado estacionário representado por uma das autofunções ${ }^{28}$ $\mathrm{Na}$ teoria quântica de campos, a mesma prerrogativa se manifesta pelo fato de que os "números de ocupação" são geralmente remetidos a ondas planas monocromáticas. Em um dos artigos muito incisivos consagrados à crítica a concepções quânticas atuais, Schrödinger estava atônito, com razão, dessa prerrogativa dos estados monocromáticos: ele pensava que ela era injustificada porque a priori um estado de superposição tem um caráter mais geral que um estado monocromático (a função $\psi=\sum c_{i} \psi_{i}$ é mais geral que a função $\psi=\psi_{i}$ ). E não obstante, o sucesso da hipótese que os estados monocromáticos têm efetivamente uma prerrogativa, dificilmente permite duvidar - contrariamente à opinião de Schrödinger - que esta prerrogativa não se justifica.

Mas tudo poderia ser explicado ao se admitir, como fui levado a fazê-lo, que os estados de superposição, tendo uma entropia menor e consequentemente uma probabilidade mais fraca que os estados monocromáticos, são de alguma maneira instáveis e que as transições quânticas de caráter irreversível (e talvez mesmo em certos casos de processos reversíveis)

\section{[p. 17]}

sempre conduzem rapidamente partículas ou sistemas para os estados monocromáticos de entropia mais elevada. Passase a ser então evidente que os estados de superposição serão em geral de breve duração e tenderão a se transformar em estados monocromáticos desde que as condições impostas à partícula ou ao sistema permitam trocas de energia ou de quantidade de movimento necessárias para isto.

Para estabelecer sobre uma base sólida a ideia que acabo de expor, será preciso demonstrar de uma forma geral, a partir da Termodinâmica oculta das partículas, que a entropia dos estados de superposição é inferior àquela dos estados monocromáticos. Eu não possuo no momento atual uma demonstração geral desse fato, mas encontrei [nessa

28 [N. T.] Na verdade, é possível fazer medidas indicando que os átomos estavam em um estado sobreposto de energia. A existência de batimentos em experimentos com o efeito Zeeman (quando se mede um observável associado a um operador que não comuta com o operador Hamiltonaniano) é um exemplo de tal fenômeno (ver, por exemplo, 11]). 
teoria] demonstrações dentro de um certo número de casos particulares. Para não alongar por demais esta exposição, eu fornecerei aqui essas demonstrações e eu me contentarei em indicar o princípio.

Escrevo inicialmente de novo, as definições (5) e 21) do potencial quântico e da entropia

$$
\mathrm{Q}=\mathrm{M}_{0} c^{2}-m_{0} c^{2} ; \quad \mathrm{S}=\mathrm{S}_{0}-k \frac{\mathrm{M}}{m_{0}}
$$

que nos leva a escrever

$$
\mathrm{S}=\mathrm{S}_{0}-k-k \frac{\mathrm{Q}}{c^{2}}
$$

Ora, nos casos que pude estudar, o potencial quântico Q é nulo em estados monocromáticos de maneira que esses estados têm a entropia "padrão" $\mathrm{S}=\mathrm{S}_{0}-k$. Nos estados de superposição, Q é diferente de zero e pode-se demonstrar facilmente que $\bar{Q}=\int Q a^{2} d \tau$ é positivo. A entropia de um estado de superposição então terá, portanto, de acordo com (28), o valor médio

$$
\overline{\mathrm{S}}=\mathrm{S}_{0}-k-k \frac{\overline{\mathrm{Q}}}{c^{2}}<S_{0}-k .
$$

Resulta dali bem que, nos casos que pude estudar, a entropia dos estados de superposição é, em média, menor do que a dos estados monocromáticos.

É interessante notar que a instabilidade dos estados de superposição parece assim estar ligada ao aparecimento nesses estados um potencial quântico positivo levando a um aumento na massa própria da partícula $\mathrm{M}_{0}$ ou do sistema, de onde, de acordo com a fórmula fundamental 21, uma diminuição da entropia. Isto parece mostrar a estreita ligação que existe entre nossa termo-

-dinâmica oculta e as noções novas que foram introduzidas pela teoria de condução e a teoria da solução dupla 29

Conclusão. - Acabo de apresentar uma visão do conjunto da evolução de meu pensamento desde o momento onde, retomando minhas ideias primitivas sobre o verdadeiro significado físico da Mecânica Ondulatória, procurei dar-lhe uma reinterpretação cujos pontos, aos meus olhos, mais essenciais são que ela restabelece uma imagem clara da partícula como um objeto muito pequeno constantemente localizado no espaço no decorrer do tempo e que ela traz à onda um caráter de um campo com existência objetiva a qual se propaga no espaço ao longo do tempo. Fui assim levado, no marco da teoria da solução dupla a retomar a "fórmula de condução" a qual atribui à partícula um movimento bem determinado, análogo àquele que a hidrodinâmica clássica atribui a uma molécula de um fluido, molécula cujo movimento se produz a cada instante ao seguir a uma das linhas de corrente do escoamento hidrodinâmico.

Obtinha assim uma imagem clara, mas, reconheci em seguida, sem dúvida muito rígida. Percebi, então, a necessidade de superpor ao movimento regular médio da partícula definida pela fórmula de condução um tipo de agitação térmica aleatória, exatamente como, ademais, no

$\overline{29}$ [N. A.] Sobre a definição de energia na [teoria da] Termodinâmica oculta das partículas, ver ver C. R. Acad. Sc. [Comptes Rendus de l'Académie des Sciences] t. 257, 1963, p. 1430. movimento real de uma molécula de um fluido se superpõe ao movimento regular definido pelas linhas de corrente uma agitação térmica aleatória. Para a molécula de um fluido, essa agitação térmica é devido a seus choques com as outras moléculas do fluido, mas para uma partícula isolada da escala microfísica uma agitação semelhante pode ser atribuída tão somente a seu contato energético permanente com um tipo de termostato oculto o qual é natural de identificar com o meio subquântico dos srs. Bohm e Vigier.

Ademais, se refletirmos sobre isso, parece bem natural que a interpretação probabilística atual da Mecânica Ondulatória, com frequência chamada sob o nome de Mecânica Quântica, conduz finalmente à introdução de noções termodinâmicas novas uma vez que ela introduz as probabilidade no comportamento de uma partícula microfísica, mesmo aparentemente isolada, e que a ligação estrita existente entre a Termodinâmica Estatística e a aparição das probabilidades nas teorias físicas sugere quase necessariamente a existência de uma Termodinâmica oculta por detrás desse comportamento. Desde muito tempo, Einstein o sentira bem e pensava que a intervenção das probabilidades em Mecânica Ondulatória devia conduzir a atribuir às partículas microfísicas um tipo de movimento browniano. Ora, quem diz movimento browniano diz também flutuações e termodinâmica.

\section{BIBLIOGRAFIA}

[indicada pelo Autor]

\section{Louis DE BROGLIE:}

Une tentative d'interprétation causale et non linéaire de la Mécanique ondulatoire : la théorie de la double solution, Gauthier-Villars, Paris, 1956.

La théorie de la Mesure en Mécanique ondulatoire, Gauthier-Villars, Paris, 1957.

L'interprétation de la Mécanique ondulatoire (J. Phys. Rad., t. 20, 1959, p. 963).

Étude critique des bases de l'interprétation actuelle de la Mécanique ondulatoire, Gauthier-Villars, Paris, 1963.

La Thermodynamique de la particule isolée (C. R. Acad. Sc., t. 2 53, 1961, p. 1078 ; t. 255, 1962, p. 807 et 1052).

D. BOHM et J.-B. VIGIER, Model of the causal interpretation of quantum theory in terms of a fluid with irregular fluctuations (Phys. Rev., t. 96, 1954, p. 208).

F. FER, J. ANDRADE E SILVA, Ph. LERUSTE et G. LOCHAK, C. R. Acad. Sc., t. 251, 1960, p. 2305, 2482 et 2662; Cahiers de Physique, $\mathrm{n}^{\circ} 129,1961$, p. 210; $\mathrm{n}^{\circ} 137,1962$, p. 1.

J. ANDRADE E SILVA et G. LOCHAK, C. R. Acad. Sc., t. 254,1962 , p. 4260 .

G. LOCHAK, C. R. Acad. Sc., t. 254, 1962, p. 4436; t. 256, 1963, p. 3601

(Manuscrito recebido em 23 de setembro de 1963).

\section{Agradecimentos}

Os autores desejam agradecer ao árbitro pelas observações e contribuições em seu parecer.

\section{Referências}

[1] H. Chang, em The Oxford Handbook of the History of Physics, editado por J.Z. Buchwald e R. Fox (Oxford University Press, Oxford, 2014), p. 473. 
[2] O. Darrigol, Séminaire Poincaré 2, 1 (2003).

[3] M. Klein, The Natural Philosopher 2, 182 (1963).

[4] M.J. Klein, Science 157, 509 (1967).

[5] A. Einstein, em Einstein Collected Papers, editado por A.J. Kox, T. Sauer, D.K. Buchwald, R. Hirschmann, O. Moses, B. Aronin, J. Stolper (Princeton Univesty Press, Princeton, 1987), p. 86.

[6] L. de Broglie, em Comptes rendus hebdomadaires des séances de l'Académie des sciences, editado por M. les secrétaires perpétuels (Gauthier-Villars, Paris, 1923), p. 507.

[7] L. de Broglie, em Comptes rendus hebdomadaires des séances de l'Académie des sciences, editado por M. les secrétaires perpétuels (Gauthier-Villars, Paris, 1923), p. 548.

[8] L. de Broglie, Recherches sur la théorie des quanta. Tese de Doutorado, Université de Paris, Paris (1924).

[9] H.R. Brown e R.A. Martins, American Journal of Physics 52, 1130 (1984).

[10] E. Schrödinger, Four Lectures on Wave Mechanics (Black and Son Limited, London, 1928).

[11] O. Pessoa Jr., Conceitos de Fúsica Quântica (Livraria da Física, São Paulo, 2005).

[12] L. de Broglie, Journal de Physique et le Radium 8, 225 (1927).

[13] L. de Broglie, em Comptes rendus hebdomadaires des séances de l'Académie des sciences, editado por M. les secrétaires perpétuels (Gauthier-Villars, Paris, 1946), p. 298.

[14] D. Bohm, Phys. Rev. 85, 166 (1952).

[15] D. Bohm, Phys. Rev. 85, 180 (1952).

[16] D. Bohm e J.P. Vigier, Phys. Rev. 96, 208 (1954).

[17] L. de Broglie, Journal de la Physique et le Radium 20, 963 (1959).

[18] L. de Broglie, The Theory of Measurement in Wave Mechanics (Gauthier-Villars, Paris, 1957).

[19] L. de Broglie, Non linear wave mechanics (GauthierVillars, Paris, 1960).

[20] L. de Broglie, em Comptes rendus hebdomadaires des séances de l'Académie des sciences, editado por M. les secrétaires perpétuels (Gauthier-Villars, Paris, 1962), p. 1052.

[21] L. de Broglie, em Comptes rendus hebdomadaires des séances de l'Académie des sciences, editado por M. les secrétaires perpétuels (Gauthier-Villars, Paris, 1962), p. 807.

[22] L. de Broglie, La thermodynamique de la particule isolée. Grands problèmes des sciences (Gauthier-Villars, Paris, 1964).

[23] L. de Broglie, Annales de l'IHP Physique théorique 1, 1 (1964).

[24] http://www.neo-classical-physics.info/thermodynamic s.html

[25] L. de Broglie, http://www.neo-classical-physics.info/t hermodynamics.html.

[26] L. de Broglie, Foundations of Physics 1, 5 (1970).

[27] L. Gao, J. Liang, C. Li e L.V. Wang, Nature 516, 74 (2014).

[28] Y. Couder, E. Fort, C.H. Gautier e A. Boudaoud, Physical review letters 94, 177801 (2005).
[29] Y. Couder, S. Protiere, E. Fort e A. Boudaoud, Nature 437, 208 (2005).

[30] Y. Couder e E. Fort, Physical review letters 97, 154101 (2006).

[31] J.W.M. Bush, Annual Review of Fluid Mechanics 47, 269 (2015).

[32] J.R. Croca, P. Castro, M. Gatta e R.N. Moreira, Annales de la Fondation Louis de Broglie 46, 1 (2021).

[33] T. Durt e M. Hatifi, Annales de la Fondation Louis de Broglie 46, 1 (2021).

[34] A. Drezet, Annales de la Fondation Louis de Broglie 46, 1 (2021).

[35] R. Ibrahim, Nonlinear Dynamics (2021), unpublished.

[36] M. Hatifi, R. Willox, S. Colin e T. Durt, Entropy 20, 780 (2018).

[37] G. Pucci, D.M. Harris, L.M. Faria e J.W.M. Bush, Journal of Fluid Mechanics 835, 1136 (2018).

[38] Y. Dagan e J.W.M. Bush, Comptes Rendus. Mécanique 348, 555 (2020).

[39] M. Durey e J.W.M. Bush, Frontiers in Physics 8, 300 (2020).

[40] P.J. Sáenz, G. Pucci, S.E. Turton, A. Goujon, R.R. Rosales, J. Dunkel e J.W.M. Bush, Nature 596, 58 (2021).

[41] https://www.larousse.fr/dictionnaires/francais/guida ge $/ 38568$

[42] M. Brillouin, em Comptes rendus hebdomadaires des séances de l'Académie des sciences, editado por M. les secrétaires perpétuels (Gauthier-Villars, Paris, 1919), p. 1318.

[43] https://aflb.minesparis.psl.eu/LDB-oeuvres/De_Brogl ie_Kracklauer.htm

[44] T.E. Phipps Jr, Toth-Maatian Review 13, 5910 (1996).

[45] L. de Broglie, Journal de Physique et le Radium 8, 65 (1927).

[46] L. de Broglie, Une tentative d'interpretation causale et non linéaire de la Mécanique ondulatoire: la théorie de la double solution (Gauthier-Villars, Paris, 1956).

[47] L. de Broglie, La théorie de la Mesure Mécanique ondulatoire (Gauthier-Villars, Paris, 1957).

[48] L. de Broglie, Étude critique des bases de l'interprétation actuelle de la Mécanique ondulatoire (Gauthier-Villars, Paris, 1963).

[49] G. Lochak, Annales de la Fondation Louis de Broglie 42, 387 (2017).

[50] G. Darmois, Les équations de la gravitation einsteinienne (Gauthier-Villars, Paris, 1927).

[51] R. Tolman, Relativity, Thermoestatistics and Cosmology (Clarendon Press Oxford, 1934).

[52] P. Langevin, J. Phys. Theor. Appl. 3, 553 (1913).

[53] R.A. Martins, Caderno Brasileiro de Ensino de Física 6, 56 (1989).

[54] R.A. Martins, Rev. Bras. Ensino Fís. 27, 11 (2005).

[55] J.A. Valadares, Revista Brasileira de Ensino de Física 15, 118 (1993).

[56] F. Fernflores, Polemos 1, 210 (2012).

[57] M. Tajmar, G. Hentsch e T. Hutsch, Measurement 172, 108917 (2021).

[58] https://www.nobelprize.org/prizes/physics/1926/perri n/facts/ 
[59] M.V. Smoluchowski, Annalen der physik 326, 756 (1906).

[60] A.A. Teske, em Dictionary of Scientific Biography, editado por C.C. Gillispie (Charles Scribner's Sons, New York, 1981), p. 496.

[61] A.K.T. Assis, K.H. Wiederkehr e G. Wolfschmidt, Weber's planetary model of the atom (Tredition Science, Hamburg, 2011).

[62] A.K.T. Assis, K.H. Wiederkehr e G. Wolfschmidt, O modelo planetário de Weber para o átomo (Apeiron, Portugal, 2014).

[63] F. Cap, Physical Review 95, 287 (1954).

[64] F. Čap, Il Nuovo Cimento (1855-1868) 3, 418 (1956).

[65] F. Aeschlimann e J.L. Destouches, Journal de Physique et le Radium 18, 632 (1957).

[66] J.L. Destouches, Journal de Physique et le Radium 13, 354 (1952)

[67] M. Bitbol, Philosophia scientiae 5, 1 (2001). 